\title{
The Prediction of Population Dynamics Based on the Spatial Distribution Pattern of Brown Planthopper (Nilaparvata lugen Stal.) Using Exponential Smoothing - Local Spatial Statistics
}

\author{
Sri Yulianto Joko Prasetyo ${ }^{1}$, Subanar $^{2}$, Edi Winarko ${ }^{2} \&$ Budi Setiadi Daryono ${ }^{3}$ \\ ${ }^{1}$ Faculty of Information Technology, Satya Wacana Christian University, Salatiga, Central Java, Indonesia \\ ${ }^{2}$ Faculty of Mathematic and Natural Science, Gadjah Mada University, Yogyakarta, Indonesia \\ ${ }^{3}$ Faculty of Biology, Gadjah Mada University, Yogyakarta, Indonesia \\ Correspondence: Sri Yulianto Joko Prasetyo, Faculty of Information Technology, Satya Wacana Christian \\ University, Salatiga, Central Java, Indonesia. Tel: 62-0298-321-212 ext 274. E-mail: sriyulianto@gmail.com
}

Received: February 17, 2013 Accepted: March 15, 2013 Online Published: April 15, 2013

doi:10.5539/jas.v5n5p209 URL: http://dx.doi.org/10.5539/jas.v5n5p209

\begin{abstract}
This study aims to predict the population dynamics of Brown Planthopper (BPH) in highly endemic areas of Central Java province, Indonesia. The research was conducted by modifying the method proposed by Legendre and Fortin (1989), through three stages. Those were predicting BPH attacks using Exponential Smoothing Holt Winter, analyzing spatial structure using I, C and Z test on Local Statistic, and making the connectivity inter the periodic predictions of planting season. The results showed that, the studied areas will experience the hotspots phenomenon based on the analysis by the method of Moran's I, Geary's C and Getis Ord Statistic. The analysis of Local Moran's and Getis Ord showed that, four counties namely Boyolali, Klaten, Karanganyar and Sragen experienced a local migration current from region to region around them, whereas other counties are independent. The migration current was influenced by topography, biotic interactions, and anthropogenic factor. Viewed from the spatial scalability in the studied areas, there are four categories of BPH population distribution; point, site, local, and landscape. BPH local migration interregion happened in the County of Klaten, Boyolali, Karanganyar and Sragen. It was caused by some factors: (1) the local climate, (2) the repetition of the use of rice plant variety in a long time, (3) the use of insecticide intensively (3-4 times in one planting period/season), and (4) the irrigation, allowing the spread of BPH larvae and eggs into its surroundings.
\end{abstract}

Keywords: population dynamic, brown planthoppers, spatial pattern, local spatial statistic

\section{Introduction}

\subsection{Background Research}

The population dynamics of Brown Planthopper (Nilaparvata lugens Stal.), hereinafter referred to the BPH, can be modeled and predicted using statistics approach (Damos \& Soultani, 2012; Hunter \& Price, 1998). BPH population dynamics are influenced by three components, of which the source of food, the natural enemies, and the biotic factors such as weather and topography (Hunter \& Price, 1998). Those three components can be a limiting factor of the BPH population development in a particular time and zone. The significant indicator that can be used as an indication of the limiting factors in the BPH population dynamics is the concentration of the population following the spatial and temporal patterns (Perry, 1997). Basically, BPH population dynamics models can be used as a signal occurrence identification of factors that affect population fluctuations and cycles, the reconstruction of population distribution, and the empirical test of the natural population dynamics phenomenon (Ellner, Seifu, \& Smith, 2002). Population dynamics can be classified into two categories : descriptive quantitative, is the identification of changes in the total population that can be used to measure the trend and predictions for the future and identification of the various physical and biological factors as the population limiting factors in order to develop a strategy of population control (Juliano, 2007).

Several countries have taken the advantage of population dynamics data for predicting the future population tendency. They have also carried out the strategy of BPH population control through the surveillance program of plant pest, which was called as insect of crop. One of the prediction methods used in pest surveillance program is 
Holt-Winters Exponential Smoothing, which is later on called as HW (Pal \& Gupta, 1994). Based on empirical studies, HW method was chosen for surveillance with some considerations, which are: simpler, adaptive and easy to be developed in the application, more accurate and reliable compared to other methods, and effective for seasonal spatiotemporal data classification on various scalability (Shmueli \& Fienberg, 2005; Unkel \& Farrington, 2010; Lu, Zeng, \& Chen, 2008; Burkom, Muphy, \& Shmuelli, 2006). HW method is appropriate for seasonal and trend pattern data, such as BPH surveillance data (Ai, 1999; Suhartono, 2008).

$\mathrm{BPH}$ is one kind of a rice plant (Oryza sativa L.) pest, which is the most destructive and has a major impact on food tenacity around the world. In Asia, BPH attacks occurred in Bangladesh, Brunei, Burma (Myanmar), China, Hong Kong, India, Japan, Cambodia, Korea, Laos, Malaysia, Nepal, Pakistan, Philippines, Singapore, Sri Lanka, Taiwan, Thailand, and Vietnam (Catindig et al., 2009; Kuno \& Dick, 1984). In 2011, BPH attacks in Indonesia covered 228,133 ha, the highest attack intensity occurred in East Java with an area of 147,857 ha and Central Java with an area of 50,390 ha. In Central Java, the minor attack intensity covered 32474 ha, 3867 ha for middle attack, 804 ha for severe attack, 13,245 ha for puso (Humas, 2012; Deptan, 2012).

Widely BPH invasion was caused by the migration capability in a remote geographical distance following seasonal wind flow (Monsoon). Physiologically, BPH is capable of flying at the speed of $5-11 \mathrm{~m} / \mathrm{sec}$ and in an altitude of 1000-3000 AD (Wada et al., 2008; Seino et al., 1987). BPH migration and distribution will lead to changes of the complex spatial and temporal structure comprising topography, climate, anthropogenic and biotic interactions factors (Wang, 2009). Distribution of population caused by topography factor is irrigation, climatic factors (duration of solar radiation, temperature, rainfall and humidity) that support the proliferation of BPH (Win et al., 2011). The population distributions caused by anthropogenic factors are the action of fertilization and using insecticides (Win et al., 2011). Furthermore, distribution of population caused by biotic interactions factor, for example regeneration ability in temperate region can only occur for three generations, whereas when migrating to the tropics, it is able to reach 12 generations per year (Bottrell \& Schoenly, 2012).

All this time, the distribution of population modeling has been done using descriptive statistical approach which comprises three methods: K-Ripley, Moran's I, and the autocorrelation function (Aukema et al., 2008). Moran's I method can be used to explain the distribution of a group of individuals in one population of hosts or predators and give an overview of the frequency distribution of the population (Ellner et al., 2001; Ellsbury et al., 1997). This study aims to predict the population dynamics based on the spatial distribution patterns of BPH population in the province of Central Java Indonesia which becomes high endemic of BPH. The research was carried out by modifying the method proposed by Legendre and Fortin (1989) as a contribution in this study. Population dynamics prediction method that uses spatial pattern approach was done in three stages: the prediction of BPH attacks using HW, the analysis of the spatial structure using test I, C and Z on Local Statistics and the connectivity inter the periodicity planting season prediction (Legendre \& Fortin, 1989).

This paper is organized as follows: Section 1 describes research background. Section 2 describes previous research as a reference of this study. Section 3 describes the theoretical background of the spatial distribution of spatial insect, spatial distribution insect pattern, and local spatial statistics. Section 4 explains the methods and stages of the research. Section 5 describes experiments containing research data, BPH attack prediction, the prediction of spatial distribution, and visualization of the spatial distribution predictions. Section 6 provides the conclusions and the future research.

\subsection{The Related Works}

Insect population dynamics phenomenon was originated from the existence of geographical factor as the limiting evolution process, like the ocean, mountains, and glaciers that were formed 400 million years ago. The acceleration of insect population dynamics had occurred when human motilities have increased drastically in the last 1000 years. It occurs through the formation of lineages in a new location (the invasion) either naturally or anthropogenically. The invasion of insect is divided into three phases, namely: the arrival phase is the process by which individuals move into new areas outside their native range, the growth phase is the process by which a population grows to a sufficient level so that extinction is highly unlikely, and spreading phase is attacking species range expansion into new areas (Liebhold \& Tobin, 2008). Insect population dynamics in various scenarios such as changes in weather conditions, changes in the landscape and the abundance of food resources in the environment can be modeled using spatial and temporal approach (Gruebler, Morand, \& Daenzer, 2007).

The insect distribution modeling through several approaches comprising are: non-linear method, the estimation of disperse index, the frequency distribution and Geostatistics. In the following decade, Geostatistical methods got more attention from ecologists as the solution in population dynamics (Tobin, Fleischer, \& Pitts, 1999). 
Geostatistics method use for the development of Integrated Pest Management model using GIS technology (Geographical Information System). This model was applied for several purposes including: modeling the pest and predator insect spatial distribution, detection and monitoring of the pest insect spatial structure in a broader scalability, the determination of high-risk of pest areas based on Agroclimatological information, and compilation of time and intensity of pest emergence prediction. The classification of attack potency was assessed based on the pest spatial and temporal tendencies comprising: the pattern of eating habits, the potency of economic impact, the pattern of population dynamics, the method of spreading and recommendations to handle the attack (Dminic et al., 2010).

Minh et al. (2002) developed an early warning model of BPH potential risks in Trungan, Thotnot District, and Cantho City Vietnam by combining several methods including multivariate regression, interpolation and Geostatistics. The study was conducted using data collected from 120 locations and 10 observation periods. The basic principle of this study was to determine the pattern of the relationship of environmental rainfall factors, maximum and minimum air temperature, air humidity and the prevalence of BPH attacks. This model can provide information about predictions of the spatial distribution occurrence prior to the BPH attack. Another observed factor is the high of water surface, the density of natural enemies and periodicity fertilization.

Song et al. (1994) conducted the use of geographic information systems study to analyze the spread movement of rice plants $(O$. sativa) insect in South Korea. The study was conducted using surveillance data from 152 observation stations of pest plant with data from the period of 1981 to 1991. The analysis of BPH spatial distribution patterns was conducted based on the results of the observation value interpolation process throughout the observation stations. This study shows that the BPH population dynamics are influenced by the temperature and migration variable.

Prasetyo et al. (2012) had conducted the research of BPH endemics determination using GISA, LISA, and Getis Ord methods in Central Java, Indonesia based on the historical data in 2001-2010. The studied areas consist of 7 counties, constituting the high BPH endemics areas. According to that research, it can be seen that the pattern of spatial object connectivity, such as BPH population centralization/clustering, the rainfall, and the geographical position of the area influences the distribution of BPH population in the whole studied areas.

\subsection{Insect Spatial Distribution}

Spatial distribution is the most dominating characteristic in the life of the insect population. Its attribute is dynamic. As a result, spatial and temporal variability will form different population structure. The knowledge of population structure both spatially and temporally will be able to provide clues to the information, which are: the spread of insect, identification of population dynamics and population density. This information will be useful in pest control framework and understanding of ecological processes that occur on a local scale (Debouzie \& Thioulouse, 1986; Pata et al., 2010). The study of the insect population spatial distribution and other biophysical factors may help us to reveal several things related to the life cycle of insect, namely: the characteristics of the environment and the spread of the individual, the development of habitat manipulation strategy especially the beneficial species, and the design of the sampling area determination, assuming that the appropriate design can help to overcome the deviations caused by spatial heterogeneity (Holland et al., 1997).The focus on the determination of the spatial pattern was to see if a population of organisms has a random, homogeneous, or the combination of random and homogeneous distribution. However, this concept is extended to see how great the size of the organisms' population convergence is (Perfecto \& Vandermeer, 2008). The spatial pattern is one of the important indicators in identifying organisms that form the dispersion of disease vectors. One type of vector-borne disease will not spread even be endemic if that disease focuses on one location only. Thus, the changes of spatial pattern will affect the changes in spreading and increasingly expanded the organism attacks (Klas, 1965). Generally, the study of spatial patterns for the ecological analysis has four objectives: testing spatial autocorrelation, spatial structure test, the causal variables test, interpolation mapping and the structure of spatial autocorrelation function. Every research goal has different methods and results, as shown in Table 1. 
Table 1. The analysis methods of spatial pattern for the ecological analysis based on the research objectives according to Legendre and Fortin (1989)

\begin{tabular}{lll}
\hline Objective & Method & Analysis \\
\hline Testing SpatialAutocorrelation & Moran's I & Correlogram Single Variable \\
& Geary'c & \\
& Mantel Test & Mantel Test between variable \\
& Mantel Correlogram & Multivariate Data \\
Description Spatial Structure & Correlogram, Variogram & Description Spatial Structure \\
& Clustering & Description Spatial Structure \\
Test Causal Model & Partial Mantel Test & \\
Estimation and Mapping & Trend Surface Analysis & Map Interpolation SingleVariable \\
Spatial Autocorrelation & Variogram & Kriging Map \\
Structure Function & & \\
\hline
\end{tabular}

The approach of the spatial patterns allows the predictive modeling and detailed mapping to be compiled in order to get a better understanding of the formation of an endemic pattern of a disease. The method of determining spatial patterns of endemicity can be done by the measurement of the studied area (Chadsuthi et al., 2010). The methods of characterization of the spatial patterns based on the research objective divided two categories: the measurement of population distribution pattern by the NNA and QA method, detecting the spatial pattern of organisms attack by the method of SAA. This can be seen in Table 2 (Chaikaew et al., 2009).

Table 2. The characteristic of spatial pattern according to Chikaew et al. (2009)

\begin{tabular}{ll}
\hline Method & Objective \\
\hline Quadrant Analysis (QA) and Nearest & The measurement of spatial pattern for \\
Neighbor Analysis (NNA) & determining population distribution \\
Spatial Autocorrelation Analysis (SAA) & $\begin{array}{l}\text { Detecting spatial patterns of organism attack } \\
\text { based on the attributes of the two scenes. }\end{array}$ \\
\hline
\end{tabular}

\subsection{Local Spatial Statistics}

Local spatial statistics was developed to meet the needs of the measurement and analysis of observation data result connectivity in a small area. That information will be useful for: (1) the identification of the population concentration or hotspot, (2) the assessment of the data stationarity structures, and (3) the identification of object distances that is out of reach of the population but has connectivity to population centers (outliers). Local spatial statistics function comprising Getis-Ord Statistics called as G and G*, Local Moran's called as I and Local Geary called as C (Getis \& Ord, 1996). Local spatial statistics function, that has oftenly been used in practice, comprises G (d) statistics, Local Moran's and Local Geary (Du \& Chen, 2003). Getis-Ord Statistics function can be seen in equation 1 and 2, and Local Geary function in Equation 4.

$$
\begin{aligned}
& G_{i}(d)=\frac{\sum_{i} w_{i j}(d) x_{j}-W_{i} \bar{x}(i)}{s(i)\left\{\left[\left((n-1) S_{1 i}\right)-W_{i}^{2}\right]\right\}^{\frac{1}{2}}}, j \neq i \\
& G_{i}^{*}(d)=\frac{\sum_{i} w_{i j}(d) x_{j}-W_{i}^{*} \bar{x}^{*}}{s^{*}\left\{\left[\left(n S_{1 i}^{*}\right)-W_{i}^{* 2}\right] /(n-1)\right\}^{1 / 2}}, \text { all } j
\end{aligned}
$$

In this equation, $n$ is identified area with the georeference $i=1,2, \ldots n$. Each $i$ value is associated by variable value of the research in studied area represented by $x$ notation. $w_{i j}(d)$ notation is spatial weight vector, with the value defined as the distance among $i$ area. Local Morans'I function according to Du and Chen (2003) is on equation 3 .

$$
I=\left(Z_{i} / S^{2}\right) \sum_{j}^{n} w_{i j} Z_{j}
$$


$Z_{i}=x_{i}-\bar{x}$ and $Z_{j}=x_{j}-\bar{x}$ is deviations from the mean value of the observed study variables. $w_{i j}$ notation is a weight matrix element which will be used for determining spatial proximity among areas. $S^{2}$ notation is the weighted mean of the deviation around. Local Geary function according to Du and Chen (2003) is on equation 4.

$$
C_{i}=\sum_{j}^{n} w_{i j}\left(Z_{i}-Z_{J}\right)^{2}
$$

Local Geary was used to calculate the difference between the squared deviations in location $i$ and location $j$.

\section{Material and Methods}

\subsection{Research Procedure}

The analysis of time series on surveillance data requires a minimum of 30 periods of observation (Ylioja et al., 1999). The criterion of number of observations area of the research that aims for the exploration of the spatial structure is at least 30 regions (Fortin \& Dale, 2005). In accordance with this approach, this study used data of 240 observations and 124 observation area. The research was conducted in four steps, as shown in Figure 1, step I is the classification of BPH outbreak data and rainfall data into three planting season, which are : main planting season, gadu planting season and dry planting season. Step II is the prediction of BPH potential attacks using the exponential smoothing holt-winters method. Step III is the modeling and mapping of the spatial distribution using local spatial statistical approaches, including: Local Moran's (I), Local Geary (C) and the Getis-Ord Statistic (G and $G *$. Step IV is the visualization of the distribution in the form of: choropleth map, $G$ and $G *$ map, Local Moran's and Geary Local Map and Boxplot. Final step is the analysis and interpretation of results based on the type of spatial patterns which consists of the three forms, namely: the pattern of concentration (Cluster Pattern), the pattern in random (Random Pattern) and the pattern of spread (Dispersed Pattern) as in Table 3 (Zhang et al., 2009).

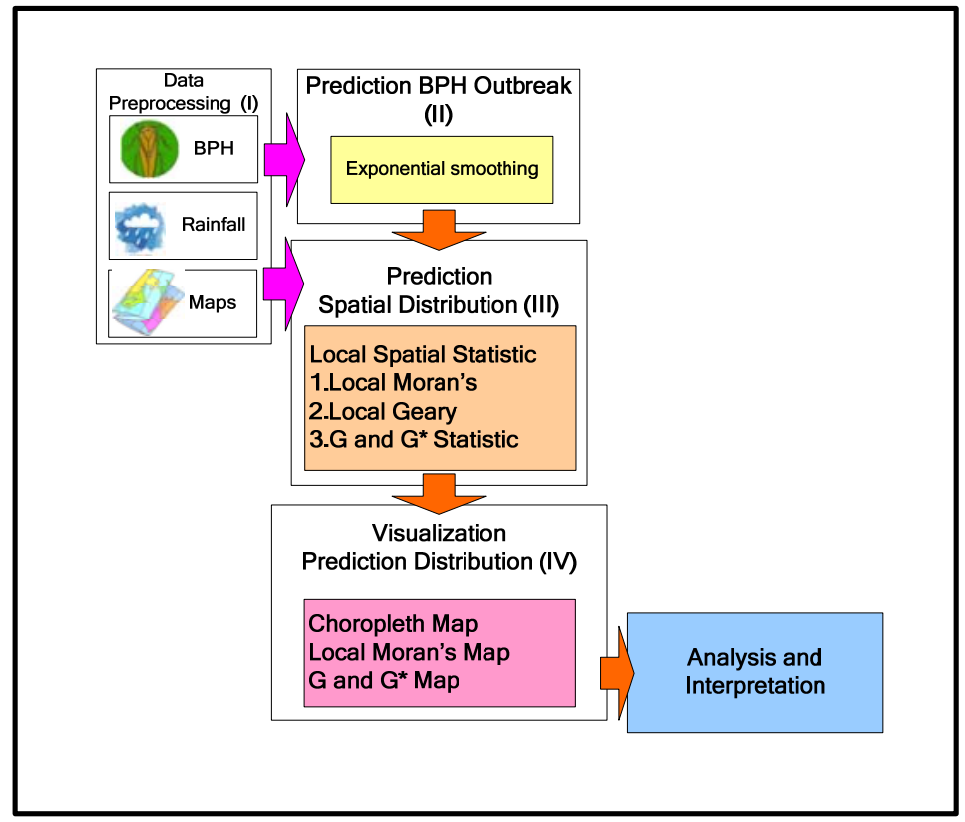

Figure 1. The research stages

Table 3. The Spatial Pattern according to Zhang et al. (2009)

\begin{tabular}{lll}
\hline Spatial Pattern & Geary's C & Moran's I \\
\hline Cluster Pattern & $0<\mathrm{C}<1$ & $\mathrm{I}>\mathrm{E}(\mathrm{I})$ \\
Random Pattern & $\mathrm{C} \sim=1$ & $\mathrm{I} \sim=\mathrm{E}(\mathrm{I})$ \\
Dispersed Pattern & $1<\mathrm{C}<2$ & $\mathrm{I}<\mathrm{E}(\mathrm{I})$ \\
\hline
\end{tabular}


Getis-Ord Statistic method in this study is used for detecting and evaluating local spatial autocorrelation on BPH distribution. The high value of Getis-Ord statistic represents the concentration occurence (cluster). The high value is notated as High (hot spots). Whereas the low value of Getis-Ord statistic represents the concentration occurrence (cluster). The low value is notated as Low (cold spots) (Truong \& Somenahalli, 2011). Francis et al. (2012) interpreted the value of $Z$ to the criteria if the value of $Z<-1.96$ called as cold spots, if the value of $Z>1.96$, it is called as hot spots with a confidence level of $p<0: 50$. The analysis of the spatial distribution of BPH is done by considering other environmental factors including anthropogenic, fertilization, predator behavior and climatic factors, rainfall.

\subsection{The Research Data}

The surveillance data used in this experiment is collected from Pest Plant Diseases Laboratory Observations Region V Surakarta, Central Java, Indonesia. The area of surveillance covering 6 counties is divided into 124 districts as the observation stations. The data periodicity was biweekly taken between 2001 and 2010. The data research consists of two forms, first is data of BPH outbreak and rainfall each of 124 records and second is map data in the form of shape files (ESRI ArcView formats). Cumulative choropleth map of BPH attack occurrence in 2001-2010 in studied area is on Figure 2.

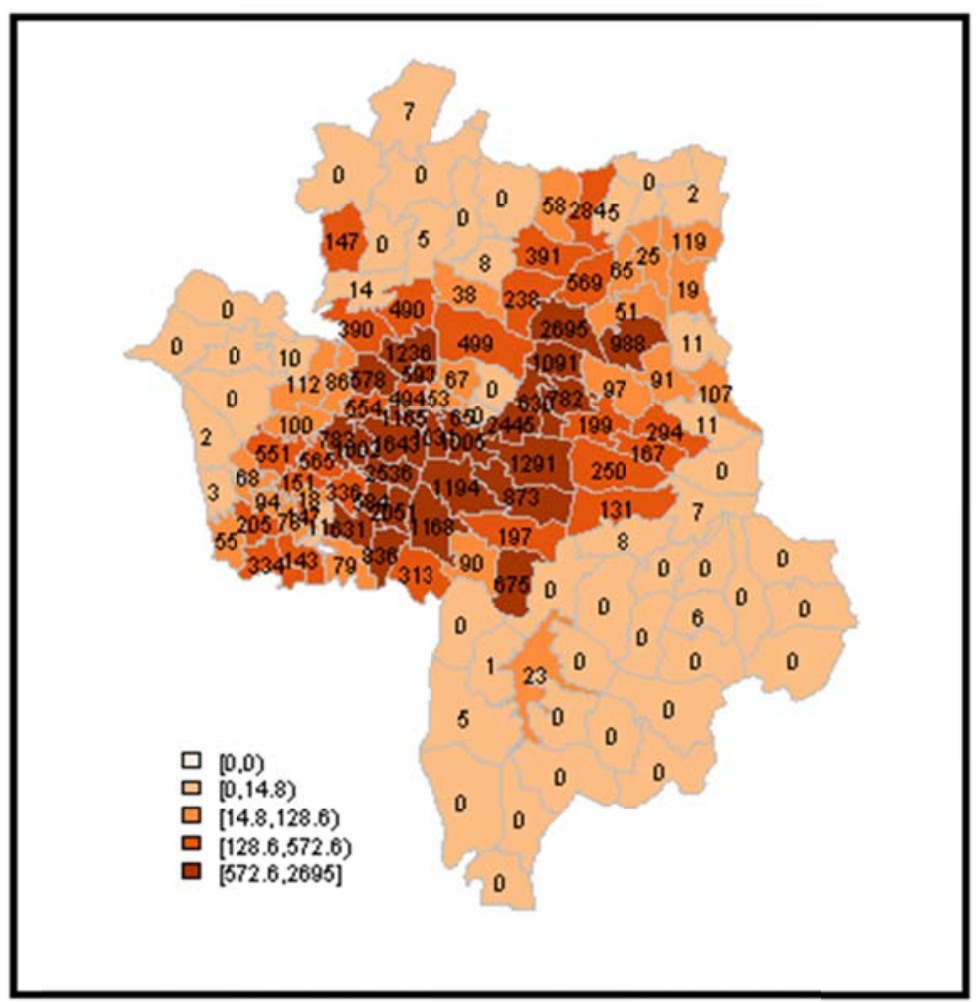

Figure 2. The choropleth map of BPH attack occurrence in 2001-2010 in studied area

From Figure 2, we can see that, the BPH distribution for 10 years is in all counties that have geographically connectivity. The term connectivity is defined as the behavior of local or individual regional movement among habitats in the same periodicity. The pattern of population movement constitutes one indicator to determine the population dynamics of insect. The limiting factor that determines the movement of the local scope includes the form of isolation (distance) and the size of the population (Matter et al., 2005). The cumulative data of attack occurrence will be the basis of predictions of BPH and BPH spatial modeling population dynamics. The prediction and modeling of spatial distribution pattern of BPH used the $\mathrm{R}$ (http://cran-project) version 2.14. Prediction version using package tseries and modeling spatial patterns used spdep package, sp, classInt, RColorBrewer, maptools, rgdal and maps. 


\section{Results}

\subsection{The Prediction BPH Outbreak}

Generally, there are three planting period: the main planting season which takes place in November-February, Gadu planting season that takes place in March to June, and a dry planting season which lasts between the month of July to October (Wijaya, 2000). Based on the BPH attack data in the planting season periodicity between the year of 2001 - 2010, BPH attack patterns have been detected since 2005 and reached its peak in 2009-2010 (Figure 3 ). Trend information (red line) and the seasonal data pattern (blue line) can be identified to see the trend of the future attacks.

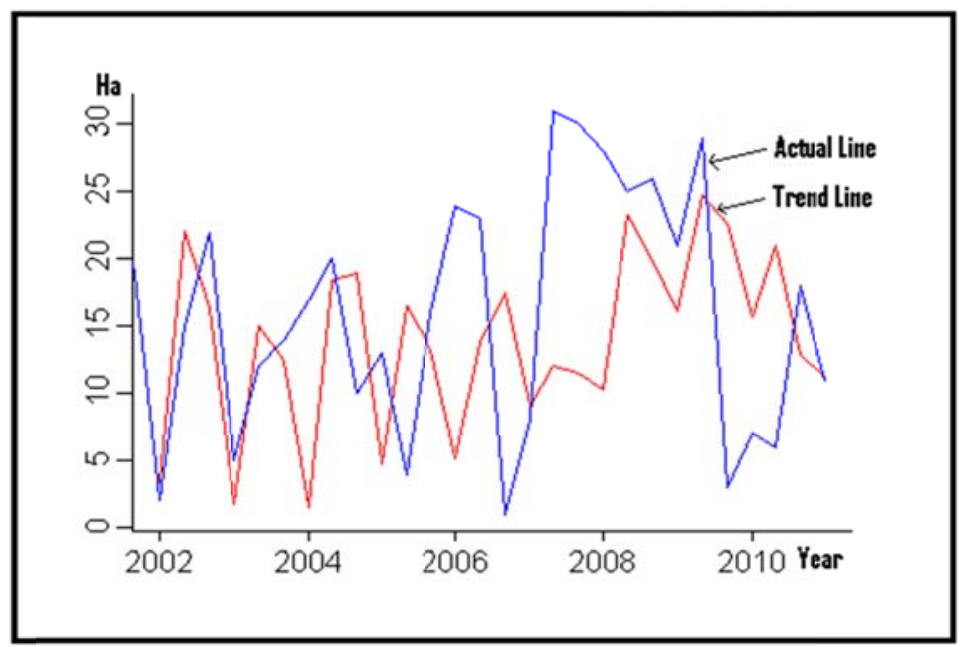

Figure 3. The data and trend line of BPH attack occurrence in studied area of 2001-2010 in planting season period

The prediction of BPH attack occurrence was conducted based on the trust significance level of 50, 80, and 95 percents for next six seasons. The result of the prediction of the BPH attack occurrence can be seen on Figure 4 . The validation of prediction result was tested using means of error (ME), which was 8.8909453, root means square error (RMSE), which was 14.8319699 , means absolute error (MAE), which was 12.1873029 , means percentage error (MPE), which was -0.7532082 , means absolute percentage error (MAPE), which was 135.8722813 , and means absolute scaled error (MASE), which was 1.4062273.

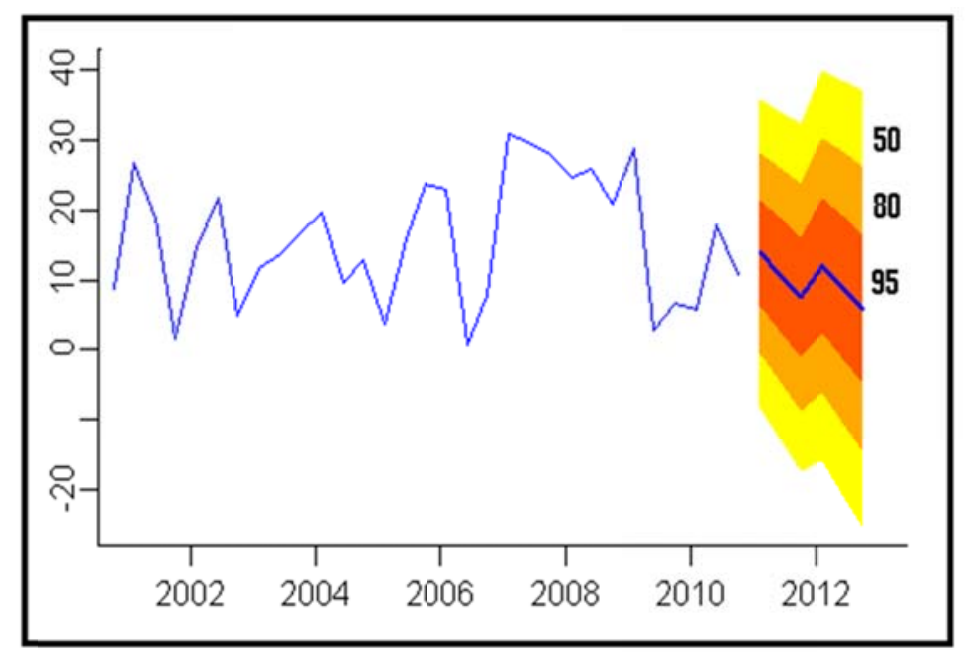

Figure 4. The prediction of BPH attack occurrence in six seasons in studied area on the trust level of $50 \%, 80 \%$ and $95 \%$ 


\subsection{The Prediction of Spatial Distribution}

The prediction of BPH population distribution per county based on the spatial pattern according to the method of Zhang et al. (2009) is in Table 4.

Table 4. The comparison of the prediction of six period-Moran's I and Geary's C spatial pattern per county according to Zhang et al. (2009)

\begin{tabular}{lllll}
\hline County & $(\mathrm{I})$ & Spatial Pattern & $(\mathrm{C})$ & Spatial Pattern \\
\hline Boyolali & 0.5238903 & Cluster & 0.5757535 & Cluster \\
Klaten & 0.1844786 & Cluster & 0.6559216 & Cluster \\
Sukoharjo & 0.0695636 & Cluster & 0.7633815 & Cluster \\
Karanganyar & -0.221604 & Cluster & 1.1410184 & Dispersed \\
Wonogiri & -0.036473 & Cluster & 0.9275305 & Cluster \\
Sragen & 0.0711412 & Cluster & 0.7198907 & Cluster \\
Surakarta & -0.404762 & Dispersed & 1.1904762 & Dispersed \\
\hline
\end{tabular}

Based on Table 4, the potential occurrence of local migration and population distribution from one area into surrounding areas through a variety of media that have connectivity can be identified. However, the high endemicity has not occured yet because of the humidity factor, as an indicator of low population increase. The low humidity was caused by the low rainfall in the studied area. The analysis of Getis-Ord Statistic is used to detect local spatial association indicated by the formation of hotspots. Hotspots represent the concentration of the number of occurrences of high BPH attacks. On the other hand, concentration of low value, called as coldspots, represents the concentration of a low number of BPH attacks occurrence (Table 5).

Table 5. Hotspots detection using the analysis of Getis-Ord Statistic

\begin{tabular}{lll}
\hline County & Getis-Ord Statistic & Spatial Pattern \\
\hline Boyolali & 0.60852186 & Hotspots \\
Klaten & 0.21746730 & Hotspots \\
Sukoharjo & 0.37549060 & Hotspots \\
Karanganyar & 0.05891069 & Hotspots \\
Wonogiri & 0 & - \\
Sragen & 0.32170523 & Hotspots \\
Surakarta & 1.00 & Hotspots \\
\hline
\end{tabular}

\section{Discussion}

\subsection{The Visualization of Spatial Distribution Prediction}

In the analysis of Local Moran's and Getis Ord map, four counties were selected because they showed high spatial connectivity in terms of local migration current from one area to its surrounding based on BPH attack widespread (in hectares). Those counties were Boyolali, Klaten, Karanganyar and Sragen. The other counties showed that BPH attacks did not have spatial connectivity, or in other words, they were independent. The area on the Local Moran's map, which is worth High-High (HH), is called as positive autocorrelation and indicated by the red colour. The $\mathrm{HH}$ area has the high BPH value, surrounded by its nearby areas which have high value as well. It is indicated that there is the local movement and migration of BPH population to nearby areas in HH area. On the other hand, the area on Local Moran's map, indicated by the white colour, has High-Low (HL) value. It means that, the area with high value is surrounded by its neighbors which have low value. This low value area is potential for the occurrence of $\mathrm{BPH}$ population distribution from the high value area, called as negative autocorrelation. While the area in yellow on the Local Moran's map is worth insignificant, it means that, it is not significant toward the distribution of $\mathrm{BPH}$ population in the nearby areas. 
Getis-Ord and G-Stat tests produced Getis-Ord and G-Stat map. The subdistrict which has Z positive value is called as positive autocorrelation $(\mathrm{HH})$, while the subdistrict with $\mathrm{Z}$ negative value is called as negative autocorrelation (LL). It is indicated that, there will be the occurrence of the movement of BPH population distribution to the nearby areas in the area with positive autocorrelation. The higher the $\mathrm{Z}$ value is, the higher BPH population will be. Consequently, it forms population clustering in that area. Based on the Local Moran's map in Boyolali, it is predicted that, there will be 3 subdistricts with $\mathrm{HH}$ value; those are Sambi, Ngemplak and Banyudono. These areas are called as positive autocorrelation and it is indicated that, there will be BPH population distribution to nearby areas with HL values (Figure 5).

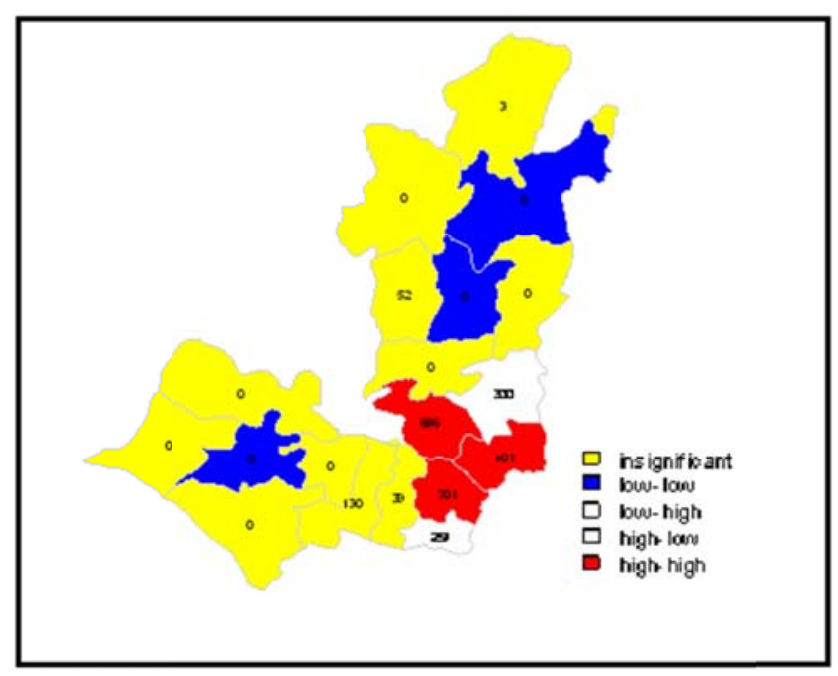

Figure 5. The prediction of local BPH migration in Boyolali based on the Local Moran's map

The map of Getis-Ord and G-Stat showed that, 7 subdistricts in Boyolali (Sambi, Ngemplak Banyudono, Simo, Nogosari, Teras and Sawit) constitute positive autocorrelation areas (HH). It is indicated that, there is the distribution of BPH population from subdistricts with high $\mathrm{Z}$ value to nearby areas with low $\mathrm{Z}$ value, and vise versa shown on Figure (6 a-b).

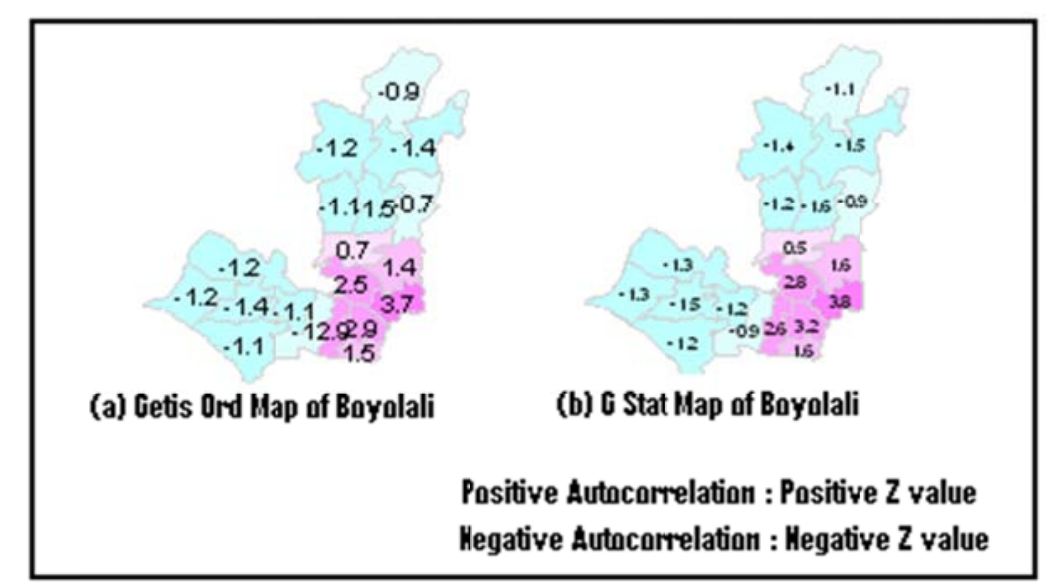

Figure 6. The prediction of BPH distribution based on the map of Getis Ord (a) and G* Statistic (b) in Boyolali

The Local Moran's map showed that, 3 subdistricts in Klaten (Juwiring, Pedan, \& Karangdowo) constitute positive autocorrelation areas. It is indicated that, there is BPH population distribution to the nearby areas, in these areas. Although the areas with negative autocorrelation have the lower BPH population, they are still potential to turn into positive autocorrelation from the areas with high values (Figure 7). 


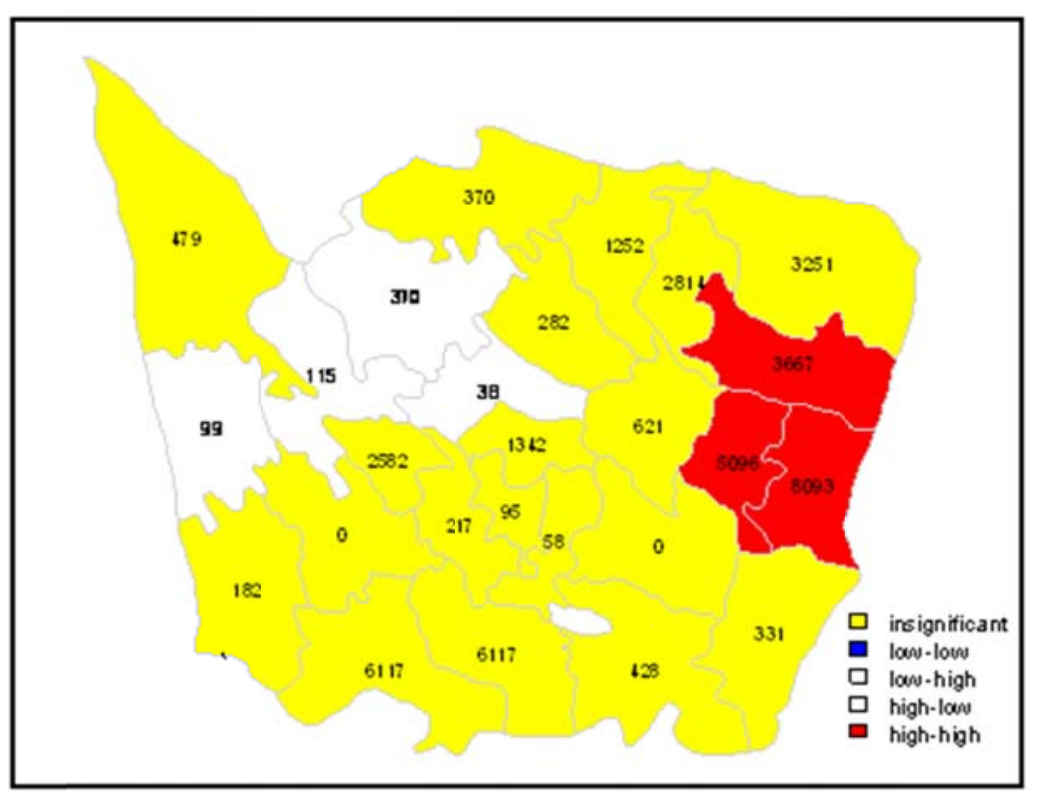

Figure 7. The prediction of BPH local migration in Klaten based on the Local Moran's map

Getis-Ord and G-Stat tests showed that, there are $\mathrm{Z}$ positive values on 10 subdistricts (Won sari, Juwiring, Karangdowo, Cawas, Pedan, Ceper, Delanggu, Prambanan, Gantiwarno and Jogonalan). The subdistricts with Z positive value are called as positive autocorrelation (High-High) and $\mathrm{Z}$ negative are negative autocorrelation (Low - Low). It is indicated that, there is BPH population distribution in the areas with positive autocorrelation. The negative autocorrelation areas are not significant toward BPH distribution (Figure 8a-b).

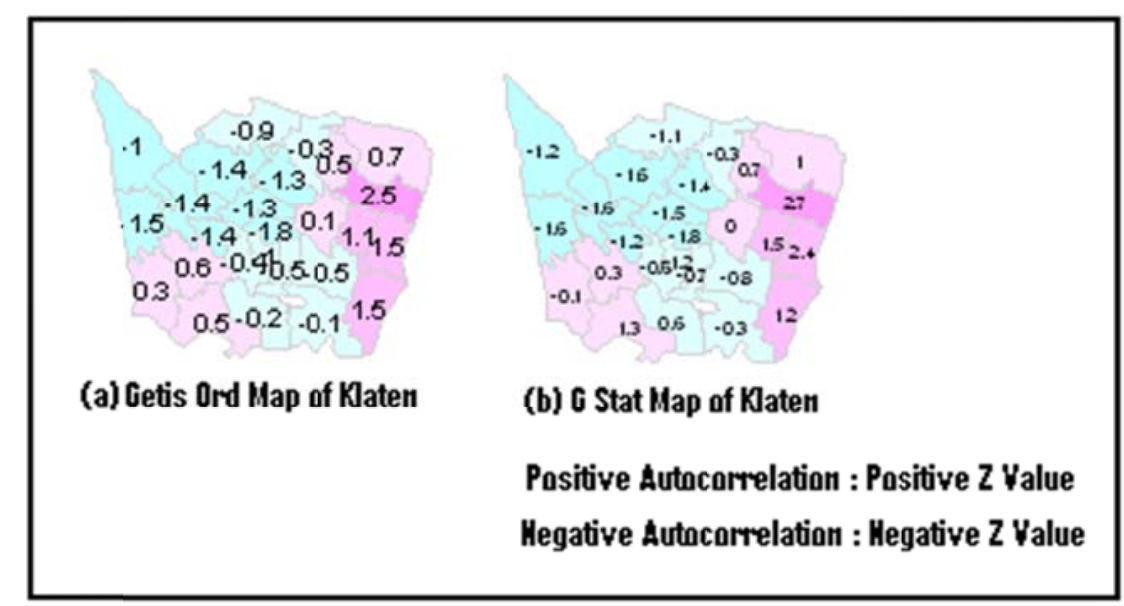

Figure 8.The prediction of BPH distribution based on Getis Ord map and G statistic map in Klaten

The Local Moran's map showed that, 3 subdistricts in Karanganyar (Tasikmadu, Jaten and Karanganyar) constitute positive autocorrelation areas. It is indicated that, there is BPH population distribution to the nearby areas in these areas. The areas with negative autocorrelation are turning into positive autocorrelation as the result of BPH population movement from the nearby areas that have positive autocorrelation values (Figure 9). 


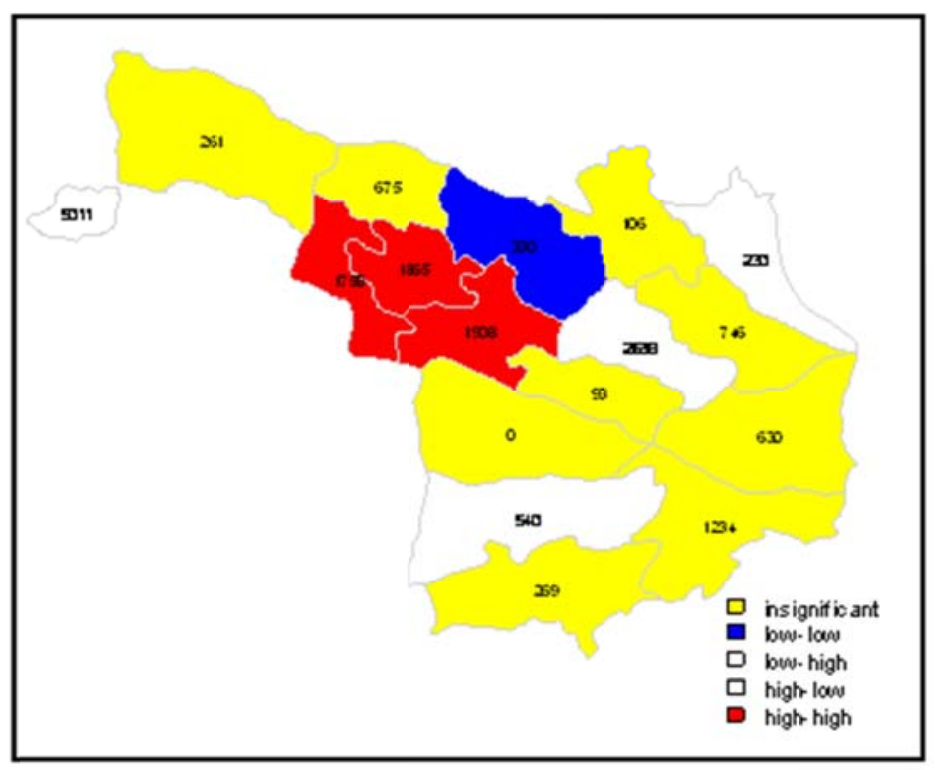

Figure 9. The prediction of BPH local migration in Karanganyar based on the Local Moran's map

Getis-Ord and G-Stat tests showed that, there was positive autocorrelation (High - High) in the county of Karanganyar (Gondangrejo, Kebakkramat, Mojogedang, Tasikmadu, Karanganyar, Jaten, Matesih and Colomadu). It is indicated that, there is BPH population distribution from the areas with high $\mathrm{Z}$ value to the low one, and vise versa (Figure $10 \mathrm{a}-\mathrm{b}$ ).

$$
\begin{aligned}
& 0.7^{3.1} 0.6 .^{0.6^{-0.7}} \cdot 0.3 \\
& 0.7-0.707 \\
& \begin{array}{lll}
.0 .7 & 03
\end{array}
\end{aligned}
$$

(a) Getis Ord Map of Karanganyar

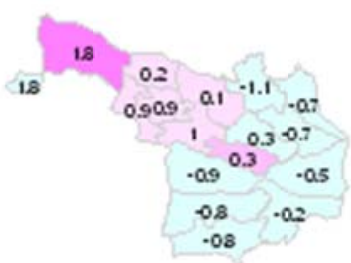

(b) G Stat Map of Karanganyar

\section{Pasitive Autocorrelation : Positive 2 Value \\ Hegative Autocorrelation : Hegative Z Value}

Figure 10. The prediction of BPH distribution based on Getis Ord map and G Statistic map in Karanganyar

The Local Moran's map showed that, Kalijambe and Plupuh subdistrict are positive autocorrelation areas. It is indicated that, there are population distribution and BPH attack clustering in these areas. On the other hand, the areas on other subdistricts indicated insignificance. It means that, they are not significant toward BPH population distribution (Figure 11). 


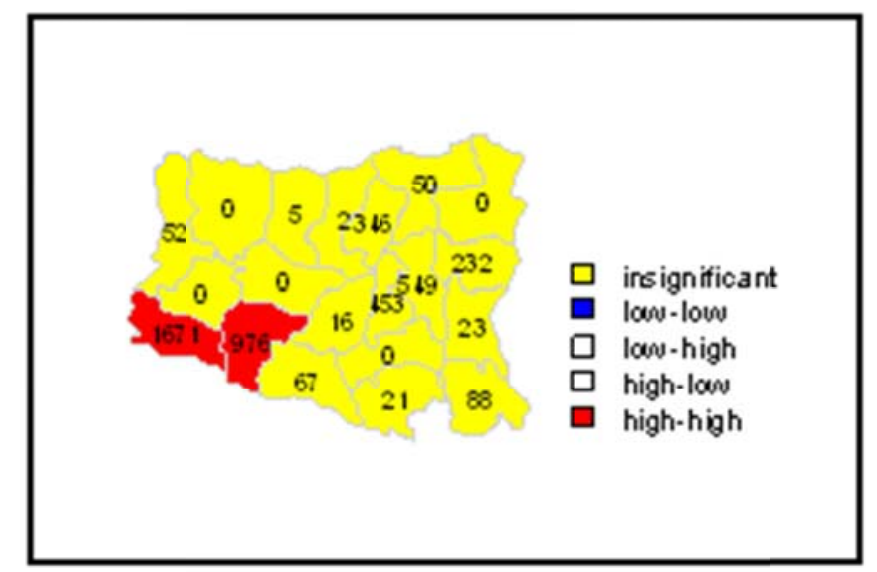

Figure 11. The prediction of BPH local migration in Sragen based on the Local Moran's map

The map on Getis-Ord and G-Stat tests showed that, there are positive autocorrelation (High - High) in 6 subdistricts (Miri, Gemolong, Kalijambe, Plupuh, Masaran and Sidoharjo). It is indicated that, there is BPH population distribution from subdistricts with high $Z$ value to the areas with low $Z$ value, or vise versa (Figure 12 a-b).

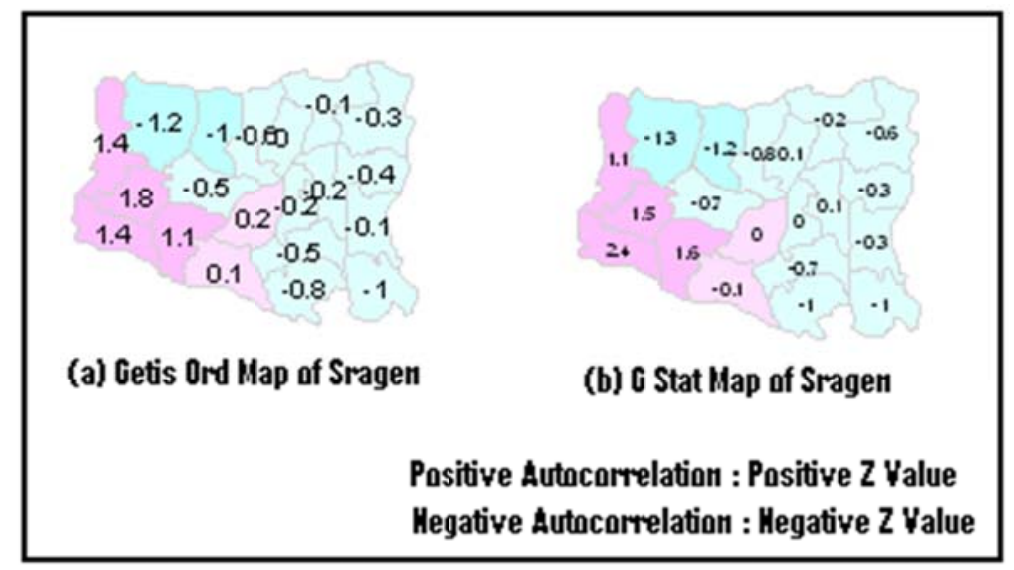

Figure 12. The prediction of BPH distribution based on Getis Ord map and G statistic map in Sragen

Figure (5) until Figure (8) showed the prediction of the BPH population distribution dynamics through local migration process of a group of large areas of high BPH attack towards the surrounding region having large areas of lower attack. Factors supporting the local migration process is spatial component connectivity in the region have similar environmental characteristics. The first factor is the spatial topography component such as irrigation network, climatic factors (duration of solar radiation, temperature, rainfall and humidity) that are almost the same. The second factor is the component of biotic interaction. That is the ability to regenerate in the new area. The third factor is the component of anthropogenic including fertilization and insecticide, which are evenly distributed throughout the studied area. This model can provide detailed information such as: (1) map of incidence, (2) map the dynamics of pest populations, and (3) the prediction of potential pest attack. The limiting factor of BPH distribution in the studied area is the distance. Based on the distribution scalability, it was categorized into four: (1) distribution distance point < 101, (2) sites, the distribution distance 103-101, (3) local, distance distribution of 104-103, and (4) landscape, distance distribution 2 x 105-104 (Hortal et al., 2010).

\subsection{The Basic Factors of BPH Population Distribution in the Studied Areas}

Generally, BPH population explosion in one field was influenced by 4 components: (1) the irrigation systems, allowing the farmers to plant more than twice a year, (2) intensively solar radiation on the field, (3) the repetition of the use of rice plant variety in a long time, and (4) intensively insecticide uses. While, the dynamic of BPH 
population, supporting the migration process from one rice field to another was influenced by 4 factors: (1) local climate and weather, (2) provision of foods, (3) competitor insects, and (4) predator organisms (Win et al., 2011). The result of the research showed the increase of population distribution and an abundance of BPH from one rice field to its surroundings (Figures 5, 6, and 7). The climate factor, especially air temperature, air humidity and rainfall, played an important role in the phenomenon of BPH population dynamics and endemics (Olanrewaju, 1998). The studied areas had the temperature of $25-30^{\circ} \mathrm{C}$. At these temperatures, there were some local ecological processes. They were (1) the occurrence of optimally insects distribution and abundance into its surroundings, (2) faster life cycles, the high regeneration pace during the season (Dyck et al., 1977), (3) the occurrence of high WBC attack (Kisimoto \& Dyck, 1976). The humidity in Asia is generally influenced by Monsoon and El Nino/La Nina phenomenon, i.e. the increase and decrease and the frequency of rains significantly (Jagtap \& Chan, 2000). The humidity in studied areas lies between $75-85 \%$, which constitutes the optimal humidity for the growth of BPH population in between 70-85\% (Dyck et al., 1977). The areas of Boyolali, Klaten, Karanganyar, and Sragen have the high rainfall and air humidity. As a result, it can be supporting factor BPH regeneration acceleration cycles. BPH larvae and eggs produced in a great amount will be washed away and brought by the water stream through the irrigation networking, broadly distributed to the surrounding ricefields. BPH larvae and eggs will sticks to rice plants and weeds until the condition of the environment, such as the decrease of rainfall, air humidity stability and optimally air temperature allowing BPH larvae and eggs to grow (Prasetyo et al., 2012). The data of the rainfall prediction in Boyolali, Klaten, Karanganyar, and Sragen can be seen in Figure 13. Based on that figure, it can be seen that in three predicted periods, 2011-2013, there were the increase of the rainfall pattern in the whole BPH clustering areas compared to the data in 2001-2010. Those two areas were potential in distributing BPH to its surroundings although both of them have the lower rainfall, and the surrounding county areas will have high BPH endemicity, characterized by the formed hotspot in LISA and GISA analysis (Prasetyo et al., 2012).
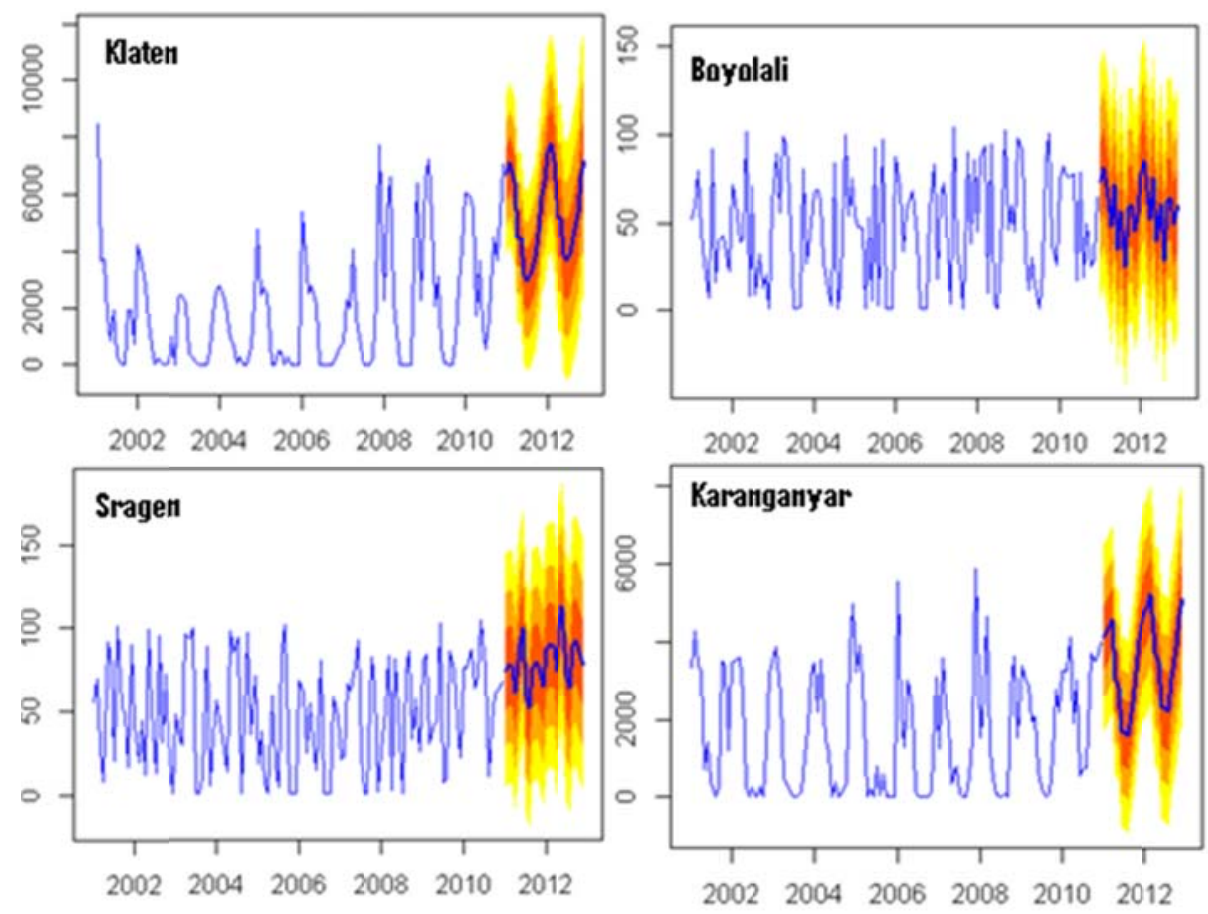

Figure 13. The prediction of the Rainfall in Boyolali, Klaten, Karanganyar, and Sragen Areas

\section{Conclusion and Future Work}

BPH population dynamics can be predicted by using Exponential - Smoothing Holt Winters and Local Spatial Statistics. The results showed that, the entire studied area ( 7 counties) showed hotspot phenomenon as much as 6 analyzed counties with the methods of Moran's I and 5 analyzed counties with Geary's C method. The comparison using Getis Ord Statistic method showed that, the entire counties experienced the hotspot phenomenon. The analysis of LISA and Getis Ord Statistic showed the areas that become the center of the attack and the potential distribution area of BPH population. The analysis of Local Moran's and Getis Ord showed four counties with high 
spatial connectivity in terms of local migration current from one area to surrounding based on the BPH attack widespread data (in hectares). The counties were Boyolali, Klaten, Karanganyar and Sragen. The other counties did not have spatial connectivity, or they were independent each other.

Some factors that support local migration process based on spatial component connectivity are topography, biotic and anthropogenic interactions. From the spatial scalability in the studied area point of view, there were four categories of BPH population distribution: point, site, local, and lanscape. Looking at it from the spatial connectivity concept, BPH local migration interregion happened in the County of Klaten, Boyolali, Karanganyar and Sragen. It was caused by some factors: (1) the local climate (the rainfall, the temperature and the air humidity), (2) the repetition of the use of rice plant variety in a long time, (3) the use of insecticide intensively (3-4 times in one planting period/season), and (4) the irrigation networking, allowing the spread of BPH larvae and eggs into its surroundings.

In our future works, we will conducts the spatial modeling and BPH migration prediction based on the spatial connectivity on regional scalability using spatial statistic approach. The prediction of BPH population migration will be done by using the seasonal BPH data and climate data classification according to local season.

\section{Acknowledgements}

This work was part of the research conducted from UPT Grand Research Directorate of Higher Education, Ministry of National Education Republic Indonesia No. 001/006.2/PP/SP/2012. We would like to thank the Observations Laboratory of Plant Pests and Diseases of the Department of Agriculture in Region Surakarta, Central of Java Indonesia and The Meteorology, Climatology and Geophysics Agency of Indonesia Central of Java Indonesia.

\section{References}

Ai, T. J. (1999). Optimalisasi Prediksi Pemulusan Eksponensial Satu Variabel Dengan Menggunakan Algoritma Non Linear Programming. Jurnal Teknologi Industri, 3(3). (In Indonesia Language). Retrieved from www.uajy.ac.id/jurnal/jti/1999/3/3/doc/1999_3_3_1.doc

Aukema, B. H., Carroll A. L., Zheng, Y., Zhu, J., Raffa, K. F., Moore, D., ... Taylor, S. W. (2008). Movement of outbreak populations of mountain pine beetle: influences of spatiotemporal patterns and climate. Ecography, 31, 348-358. http://dx.doi.org/10.1111/j.0906-7590.2007.05453.x

Bottrell, D. G., \& Schoenly, K. G. (2012). Resurrecting the ghost of green revolutions past: The brown planthopper as a recurring threat to high-yielding rice production in tropical Asia. Journal of Asia-Pacific Entomology, 15, 122-140. http://dx.doi.org/10.1016/j.aspen.2011.09.004

Burkom, S. H., Muphy, S. P., \& Shmuelli, G. (2006). Automated Time Series Forecasting for Biosurveillance. Retrieved from http://papers.ssrn.com/sol3/papers.cfm?abstract_id=923635.

Catindig, J. L. A., Arida, G. S., Baehaki, S. E., Bentur, J. S., Cuong, L. Q., Norowi, M., ... Lu, Z. (2009). Situation of Planthoppers in Asia. Retrieved from http://Phillipine.ag.udel.edu/delpha/535.pdf

Chadsuthi, S., Modchang, P. C., Kanthang, P., Triampo, D., \& Nuttavut, N. (2010). Stochastic Modeling and Combined Spatial Pattern Analysis of Epidemic Spreading. Bangkok Thailand International Journal of Engineering and Natural Sciences, 4, 4.

Chaikaew, N., Tripathi, N. K., \& Souris, M. (2009). Exploring spatial patterns and hotspots of diarrhea in Chiang Mai, Thailand. International Journal of Health Geographics, 8, 36. http://dx.doi.org/10.1186/1476-072X-8-36

Damos, P., \& Soultani, M. M. S. (2012). Temperature-Driven Models for Insect Development and Vital Thermal Requirements. Psyche, Vol. 2012, Article ID, 123405. http://dx.doi.org/10.1155/2012/123405

Debouzie, D., \& Thioulouse, J. (1986). Statistics to Find Spatial and Temporal Structures in Populations. NATO ASI Series, Vol G11, Pest Control: Operations and Systems Analysis in Fruit Fly Management. http://dx.doi.org/10.1007/978-3-642-70883-1_18

Dminić, I., Kozina, A., Bažok, R., \& Barčić, J. I. (2010). Geographic information systems (GIS) and entomological research: A review. Journal of Food, Agriculture \& Environment, 8(2), 1193-1198. Retrieved from http://www.isfae.org/scientficjournal/2010/issue2/pdf/environment/e63.pdf.

Du, D., \& Chen, F. (2003). The Application of Local Spatial Statistics in Regional Economics Analysis. Proceeding of the $21^{\text {st }}$ International Cartographic Conference. 
Dyck, V. A., Misra, B. C., Alam, S., Chen, C. N., Hsieh, C. Y., \& Rejesus, R. S. (1977). Ecology of the brown planthopper in the tropics. Brown planthopper: Threat to Rice Production in Asia. Los Baños. Philippines: Central Rice Research Institute.

Ellner, S. P., McCauley, E., Kendall, B., Briggs, C. J., Parveiz, R. H., Wood, S. N., ... Murdochk, W. W. (2001). Habitat structure and population persistence in an experimental community. Nature Vol 4122 Agust. 2001. http://dx.doi.org/10.1890/0012-9658(2002)083[2256:FPDMTT]2.0.CO;2

Ellner, S. P., Seifu, Y., \& Smith, R. H. (2002). Fitting Population Dynamic Models To Time Series Data By Gradient Matching. Ecology, 83(8), 2256-2270. Retrieved from http://www.esajournals.org/doi/abs/10.1890/0012-9658\%282002\%29083\%5B2256\%3AFPDMTT\%5D2.0C $\mathrm{O} \% 3 \mathrm{~B} 2$.

Ellsbury, M. M., Woodson, W. D., \& Clay, S. A. (1997). Geostatistical Characterization of the Spatial Distribution of Adult Corn Rootworm (Coleoptera: Chrysomelidae) Emergence. Environmental Entomology, 27(4). http://www.entsoc.org/PDF/Pubs/Periodicals/EE/EETOCS/PDF/en049800910.pdf

Fortin, M. J., Dale, M. R. T., \& Hoef, J. (2002). Spatial analysis in ecology, Encyclopedia of Environmetrics. Chichester: John Wiley \& Sons, Ltd.

Francis, M. R., Rakesh, P. S., Mohan, V. R., Balraj, V., \& George, K. (2012). Examining spatial patterns in the distribution of Low Birth Weight babies in Southern India the role of maternal, socio-economic and environmental factors. Int J Biol Med Res, 3(1), 1255-1259.

Getis, A., \& Ord, J. K. (1996). Local Spatial Statistics: an Overview. In P. Longley, \& M. Batty (Eds.), Spatial Analysis: Modeling in a GIS Environment (Cambridge: Geoinformation International) (pp. 261-277).

Gruebler, M. U., Morand, M., \& Daenzer, B. N. (2007). A predictive model of the density of airborne insects in agricultural environments. Agriculture, Ecosystems and Environment, 123(2008), 75-80. http://dx.doi.org/10.1016/j.agee.2007.05.001

Holland, J. M., Perry, J. N., \& Winder, L. (1997). The within-field spatial and temporal distribution of arthropods in winter wheat. The Game Conservancy Trust, Fordingbridge, Hants., SP6 1EF, UK. Bulletin of Entomological Research, 89, 499-513.

Hortal, J., Pascual, R., Sanders, N., \& Rahbek, C. (2010). Understanding (insect) species distributions across spatial scales. Ecography, 33, 51-53. http://dx.doi.org/10.1111/j.1600-0587.2009.06428.x

Humas. (2012). Organisme Pengganggu Tanaman 'Wereng Coklat' Merupakan Hama Global, DinHubKominfo Kantor Pemerintah Daerah Jateng. (In Indonesia Language). Retrieved from http://www.jatengprov.go.id/?document_srl=28083

Hunter, M. D., \& Price, P. W. (1998). Cycles in insect populations: delayed density dependence or exogenous driving variables. Ecological Entomology, 23, 216-222. http://dx.doi.org/10.1046/j.1365-2311.1998.00123.x

Jagtap, S. S., \& Chan, A. K. (2000). Agrometeorological aspects of agriculture in the sub-humid and humid zones of Africa and Asia. Agricultural and Forest Meteorology, 103, 59-72. http://dx.doi.org/10.1016/S0168-1923(00)00117-9

Juliano, S. A. (2007). Population Dynamic. AMCA Bulletin No. 7, vol. 23, Supplement to NO. 2. Retrieved from $\mathrm{http}: / /$ www.un.org/millenniumgoals/pdf/Think\%20Pieces/15_population_dynamics.pdf

Kisimoto, R., \& Dyck, V. A. (1976). Climate and rice insects, Central Agricultural Experiment Station, Konosu, Saitama, Japan. Proceedings of the symposium on climate \& rice (pp. 367-391). Los Baños, Laguna.

Klas, E. F. (1980). Population Densities and Spatial Patterns of the Aphid Tristeza Vector, Toxoptera citricida Kirk. Proceedings of the conference - International Organization of Citrus Virologists (pp. 83-87).

Kuno, E., \& Dick, V. A. (1984). Dynamics of Philipines and Japanese Populations of the Brown Planthoppers: Comparison of Basic Characteristics. Retrieved from http://140.112.100.36/old/chinese/publication/journal/pdf/c0402/4-2-3.pdf

Legendre, P., \& Fortin, M. J. (1989). Spatial Pattern and Ecological analysis. Vegetatio, 80, 107-138. http://dx.doi.org/10.1007/BF00048036

Liebhold, A. M., \& Tobin, P. C. (2008). Population Ecology of Insect Invasions and Their Management, Forest Service, U.S. Department of Agriculture, Northern Research Station, Morgantown, West Virginia. Annu. Rev. Entomol., 53, 387-408. http://dx.doi.org/10.1146/annurev.ento.52.110405.091401 
Lu, H. M., Zeng, D., \& Chen, H. (2008). Prospective Infectious Disease Outbreak Detection Using Markov Switching Models, Management Information Systems Department, University of Arizona, Tucson. Retrieved from http://ai.arizona.edu/intranet/papers/Lu_Prospective_ID_TKDE_Preprint.pdf

Matter, S. F., Roslin, T., \& Roland, J. (2005). Predicting immigration of two species in contrasting landscapes: effects of scale, patch size and isolation. Oikos, 111, 359-367. http://dx.doi.org/10.1111/j.0030-1299.2005.14127.x

Minh, V. Q., Quynh, P., Hieu, P. T. M., Quang, T. C., \& Hieu, N. M. (2002). An Initial Method in Application of GIS (Geographical Information System) in Spatial Delineation for Early Warning The Potential Risk of Brown Planthoppers (Nilaparvata lugen Stal.) A Case Study in Trungan Village, Thotnot District, Cantho City, Vietnam, Remote Sensing Lab, College of Agricultural \& Applied Biology, Cantho University.

Olanrewaju, R. M. (1998). Effect of Climate on Pests Outbreak in the Sub-Humid Region of Nigeria: A Case Study of Kabba, Kogi State. International Journal of Urban and Regional Affairs, 2(2), 19-23.

Pal, S. K., \& Gupta, D. (1994). Pest Control. Training and Fellowships Program, International Crops Research Institute for the Semi-Arid Tropics Patancheru 502 324, Andhra Pradesh, India. Retrieved from http://www.icrisat.org/what-we-do/learning-opportunities/lsu-pdfs/sds.15.pdf

Pata, M. P., Alvarez, M. X. R., Perez, V. L., Pulpeiro, E. F., \& Suarez, C. C. (2010). Modelling spatial patterns of distribution and abundance of mussel seed using Structured Additive Regression models, 2010. Statistics \& Operations Research Transactions SORT 34 (1) January-June 2010, 67-78.

Perfecto, I., \& Vandermeer, J. (2008). Spatial Pattern and Ecological Proocess in The Coffee Agro forestry System, School of Natural Resources and Environment, University of Michigan, Ann Arbor, Michigan 48109 USA. Ecology, 89(4), 915-920. http://dx.doi.org/10.1890/06-2121.1

Perry, J. N. (1997). Some Unresolved Issues In Non-Linier Population Dynamics, Department of Entomology \& Nematology, Rothamsted Experimental Station. Harpenden, Herts. AL5 2JQ. United Kingdom. Question, 21(12), 269-272. Retrieved from http://www.idescat.cat/sort/questiio/questiiopdf/21.1.13.Perry.pdf

Prasetyo, S. Y., Subanar, J., Winarko, E., \& Daryono, B. S. (2012). Endemic Outbreaks of Brown Planthopper (Nilaparvata lugens Stal.) in Indonesia using Exploratory Spatial Data Analysis. IJCSI International Journal of Computer Science Issues, 5(1), 162-171.

Seino, H., Shiotsuki, Y., Oya, S., \& Hirai, Y. (1987). Prediction of Long Distance Migration of Rice Planthoppers to Northern Kyushu Considering Low-Level Jet Stream, Kyushu National Agricultural Experiment Station, Chikugo, Fukuoka 833, Japan.

Shmueli, G., \& Fienberg, S. E. (2005). Current and Potential Statistical Methods for Monitoring Multiple Data $\begin{array}{llll}\text { Streams for Bio-Surveillance. } & \text { Retrieved }\end{array}$ http://www.rhsmith.umd.edu/faculty/gshmueli/blog/potentialmonitoringmethods.pdf

Song, Y. H., Heong, K. L., Lazaro, A. A., \& Yeun, K. S. (1994). Use of geographical information systems to analyze large area movement and dispersal of rice insects in South Korea. Selected Papers From The International Rice Research Conference, International Rice Research Institute.

Suhartono (2008). Analisis Data Statistik dengan R, Jurusan Statistika ITS Surabaya (In Indonesia Language).

Tobin, P. C., Fleischer, S. J., \& Pitts, C. W. (1999). Spatio-Temporal Dynamics of Resident and Immigrating Populations of Carcinops pumilio (Coleoptera: Histeridae) in High-Rise Poultry Facilities. Journal of Medical Entomology, 36(52). Retrieved from http://www.ncbi.nlm.nih.gov/pubmed/10534950

Truong, L. T., \& Somenahalli, S. V. C. (2011). Using GIS to Identify Pedestrian-Vehicle Crash Hot Spots and Unsafe Bus Stops, University of South Australia. Journal of Public Transportation, 14(1), 99-114.

Unkel, S., \& Farrington, C. P. (2010). Statistical methods for the prospective detection of infectious disease outbreaks: A review. Arom http://www.researchgate.net/publication/227762584_Statistical_methods_for_the_prospective_detection_of _infectious_disease_outbreaks_a_review

Wada, T., Ito, K., Takahashi, A., \& Tang, J. (2008). Starvation tolerance of macropter brownplanthopper, Nilaparvata lugens, from temperate, subtropical, and tropical populations in East and South-East Asia, Retrieved from http://journals.ohiolink.edu/ejc/article.cgi?issn=00138703\&issue=v130i0001\&article=73_stombppieasa 
Wahono, S. (2012). Prakiraan Serangan WBC pada padi di Indonesia MT 2011/2012, BPOPT Tanaman Pangan Kementerian Pertanian RI., http://tanamanpangan.deptan.go.id/doc_upload/MHpwbc.pdf (In Indonesia Language).

Wang, C., Li, D., Hu, Y., Wu, X., \& Qi, Y. (2009). Research of spatio-temporal analysis of agricultural pest, LIESMARS. International Symposium on Spatial Analysis, Spatial-Temporal Data Modeling, and Data Mining. Retrieved from http://adsabs.harvard.edu/abs/2009SPIE.7492E.117W

Wijaya, S. (2000). Peraturan Bupati tentang Pola Tanam dan Rencana Tanam Pada Daerah Irigasi di Kabupaten Sukoharjo Tahun 2010/2011 (In Indonesia Language).

Win, S. S., Muhamad, R., Ahmad, Z. A. M., \& Adam, N. A. (2011). Population Fluctuations of Brown Plant hoppers Nilaparvata lugen Stal. and White Backed Plant Hopper Sogatella Furcifera Horvath on Rice. J. Entomol., 8(2), 182-190.

Ylioja, T., Roininen, H., Ayress, M. P., Rousi, M., \& Price, P. W. (1999). Host-driven population dynamics in an herbivorous insect, Punkaharju Research Station, Finnish Forest Research Institute, FIN-58450 Punkaharju, Finland. Proc. Natl. Acad. Sci. USA, 96, 10735-10740. http://dx.doi.org/10.1073/pnas.96.19.10735

Zhang, D., Mao, X., \& Meng, L. (2009). A Method Using ESDA to Analyze the Spatial Distribution Patterns of Cultural Resource. The International Archives of the Photogrammetry. Remote Sensing and Spatial Information Sciences, 38, Part II. 